\title{
EL ELEMENTO AUTOBIOGRÁFICO EN EL RELATO DE FICCIÓN: LA OBRA DE ELVIRA MUJČIĆ
}

THE AUTOBIOGRAPHICAL ELEMENT IN FICTIONAL NARRATIVE: THE WORK OF ELVIRA MUJČIĆ

Sara Velázquez García

Universidad de Salamanca

\section{Resumen:}

El artículo trata la producción literaria de la escritora Elvira Mujčić. A través del análisis de su obra hemos podido constatar cómo la autora, de origen bosnio y nacionalizada italiana, desarrolla todas sus novelas con un marcado tinte autobiográfico. El artículo analiza precisamente este factor y cómo la propia Mujčić nos guía en un viaje para descubrir una identidad fragmentada.

\section{Palabras claves:}

literatura italiana de la inmigración, Elvira Mujčić, autobiografía, escritoras inmigrantes.

\section{Abstract:}

This article deals with the literary output of Elvira Mujčić. Through the analysis of her work we were able to prove how the author, of Bosnian origin but with Italian citizenship, develops all her novels with a pronounced autobiographical hint.

This study underlines precisely this element and how Mujčić guides us through a journey whose final destination is the discovery of a fragmented identity.

\section{KEY WORD:}

migrant literature in Italian, Elvira Mujčić, autobiography, immigrant writers. 


\section{LA AUTOBIOGRAFÍA EN LA LITERATURA DE LA INMIGRACIÓN}

El relato testimonial y el elemento autobiográfico forman parte de la propia idiosincrasia de la literatura de la inmigración desde sus inicios en la década de los noventa del pasado siglo. La mayoría de los escritores que forman parte de este género aluden en algún momento de su producción a sus propias experiencias y acuden al género autobiográfico como recurso para darse a conocer ellos mismos como personas y para informar al país que los acoge de su proceso de integración y de sus problemas y preocupaciones, justificando de algún modo su necesidad de escribir y de hacerlo en una lengua que no es la materna.

Las novelas que marcan el inicio de este tipo de literatura son producciones escritas a cuatro manos en las que sus autores se narran a sí mismos y que, tomando como punto de partida su llegada a Italia y su experiencia migrante, realizan un autorretrato vital. En estos primeros años noventa a los que hacíamos referencia se publican tres autobiografías noveladas fundamentales para entender el género: Io, venditore di elefanti. Una vita per forza fra Dakar, Parigi e Milano del senegalés Pap Khouma, Immigrato del tunecino Salah Methnani, Chiamatemi Ali del marroquí Mohamed Bouchane.

Estas autobiografías se narran desde un punto de vista retrospectivo sobre su propio pasado ligado a un país, a una cultura y a una lengua que forman parte de una identidad que ante la perspectiva de la integración se ve mutada, alterada y enriquecida. Las novelas se articulan normalmente a caballo entre esa retrospectiva que ha conformado su vida hasta el momento y la prospectiva de lo que puede suceder a partir de ahora. Estos escritos, por lo tanto, no son sólo el testimonio de una experiencia fundamental en sus vidas, sino que sus autores se erigen como narradores de una nueva Italia en la que su propia historia personal entronca con la historia colectiva de todo un país, el de acogida.

No obstante, una vez superada esta primera fase de carácter sobre todo testimonial, la literatura de la inmigración sufre un momento crítico. Ante una situación en la que los medios de comunicación y las editoriales prestan cada vez menos atención a los escritores inmigrantes, estos buscan otras maneras de darse a conocer: desaparece la figura del coautor ${ }^{1}$ y se centran en temáticas diferentes sin abandonar la esencia migrante. La autobiografía y el testimonio de la experiencia dan paso a otro tipo de temas, ligados, eso sí, en la mayoría de los casos a su condición de migrantes pero buscando innovar y alejarse de la etiqueta de escritores migrantes investigando nuevas formas y nuevos contenidos.

1 Las primeras novelas a las que nos hemos referido fueron escritas siguiendo la técnica a cuatro manos. narrador y protagonista de la historia redacta la obra con la ayuda de un escritor o periodista. Por ejemplo, Pap Khouma y Oreste Pivetta o Salah Methnani y Mario Fortunato. i più consapevoli tra gli scrittori abbandonano le forme della testimonianza, in versi e prosa, del viaggio e dell'integrazione, felice o meno, per dar mani ad opere che naturalmente confluiscono nel mainstream della produzione autoctona. Non più la biografia romanzata, perciò, la tranche de vie più o meno dolorosa o traumatica, toni di denuncia da docu-fiction, quanto piuttosto le forme magiormente in voga del reportage, del noir metropolitano o del racconto per bambini; i modi d11'iog a del reportage, del noir metropolitano o del racconto per bambini; i modi dell'ironia e dell'umorismo, del grottesco, della suspense. Si tratta spesso, come vedremo, di espedienti ad alto gradiente simbolico, in ogni caso, di comprovata efficacia per soggetti in cerca di cittadinanza culturale. (Fracassa 2010: 181)

Estos nuevos contenidos, como afirma el profesor Serge Vanvolsem², se dedicarán a analizar a Italia y a los italianos y a hablar del país de acogida tal y como ellos lo perciben y, por otro lado, cobra fuerza la temática de la identidad en forma de crisis, sentimiento de duplicidad identitaria, conflictos o rebelión.

Asimismo, la nostalgia formará parte de esta etapa, los autores extrañan su país y así nos lo transmiten. El dolor provocado por la nostalgia les lleva también a describir el país que ellos vivieron y los condicionantes que hicieron que lo abandonaran: una parte importante de esta literatura nos habla de guerras, de conflictos políticos, de fronteras que cambian o países que desaparecen, de marginaciones, humillaciones y censura en sus propios países. Este será el caso de alguna manera de la obra escrita por la autora de origen bosnio, Elvira Mujčić, quien tras su primera novela de corte autobiográfico ha publicado otras cuatro en las que, partiendo de experiencias propias y ajenas relata diferentes historias con varios denominadores comunes: su país de origen, la guerra y personajes que han emigrado a Italia.

Podemos afirmar en realidad que, a pesar de las anteriores consideraciones, la literatura autobiográfica sigue muy presente en la literatura de la inmigración más contemporánea, como afirma Chiara Mengozzi (2013: 123) "le narrazioni in prima persona rette da un patto qualificabile come autobiografico, indipendentemente dalla componente finzionale che può riguardare i contenuti, attraversano l'intero corpus della «letteratura migrante» dalle origini a oggi".

La misma autora (2013: 125) afirma que, entre otros, los inmigrantes procedentes de la zona de los Balcanes que se adentran en el mundo de la literatura están "facilmente autorizzati" a hablar y a escribir en Italia si lo hacen en clave autobiográfica para relatar la guerra y sus consecuencias; este es el caso precisamente de Elvira Mujčić. El trauma sufrido por estos autores parece legitimarlos frente al mercado editorial para liberarse, a través de la escritura, de la carga vital que sufren por todo lo vivido.

Los inmigrantes permanecen ligados a sus orígenes a través de los recuerdos y la necesidad de mantener este vínculo es especialmente importante en el caso de los

\footnotetext{
2 http://www.eksetra.net/studi-interculturali/relazione-intercultura-edizione-2004/relazione-di-serge-
} vanvolsem/[Fecha de consulta: 29/10/16]. 
exiliados de la antigua Yugoslavia ya que es el único patrimonio que les queda de sus raíces; es una lucha por mantener vivo su pasado, conscientes de que el país del que provienen ya sólo existe en su memoria.

Siamo abituati a perdere. Ogni giorno qualcuno intorno a noi si allontana o sparisce, un'amicizia o un amore impallidisce o si estingue, la morte si porta via uno dei nostri. Perdere fa parte del nostro destino. Però è raro perdere un paese. A me è capitato. Non parlo di uno stato o di un regime, ma proprio del paese dove sono nato, e che, ancora ieri soltanto, era il mio. Non c’è più. (Matvejević, 1996: 95)

Esta misma imagen aparece reflejada en las palabras de uno de los personajes de la autora que motiva este artículo:

\section{«[...] A me interessa sapere, vorrei conoscere, e sto leggendo questo libro in italiano perché là non li vendono in serbo-croato e...». \\ «Vedi! Lo vedi? La chiami serbo-croato, questa lingua, come tuo padre continua a dire che è jugoslavo. Ma siete semplicemente matti! Perché quella lingua non esiste più e quel Paese non c'è più!» (Mujčić, 2009: 88)}

Los ejemplos son numerosos en la obra de esta escritora, encontramos multitud de pasajes en los que se habla de esa patria perdida.

Dove era morta la Jugoslavia? Forse non in luogo solo. E con lei, loro erano scomparsi, senza che scoprissimo mai dove.

Con quello Stato eravamo svaniti anche noi, quel noi composto da ventitré milion di individui chiamati jugoslavi, cancellati dalle cartine geo-politiche, riallocat all'interno dei confini più stretti delle nostre piccole Repubbliche indipendenti, e gli altri, a quel punto nemici, erano sempre di pì̀ Il noi era diventatondenti, e gli altri, a quel punto nemici, erano sempre di più. II noi era diventato altro, da fratelli siamo diventati nemici guirati. Persino la lingua che parlavano, il serbocroato, non si chiamava più così, hanno deciso che bisognava darle un altro nome per non confonderci, per distinguerci. Quindi abbiamo chiamato la stessa lingua en tre modi diversi. (Mujčić, 2016: 103 - 104)

Como podemos ver en estas citas, no se trata únicamente de una patria perdida aparece también el concepto de la lengua que cambia de nombre con el objetivo de tamizar una cultura mestiza para obtener una identidad pura "proteggendola dalle contaminazioni" (Mujčić, 2016: 104).

Estos autores no se ciñen exclusivamente a los cánones autobiográficos, si bien es cierto que la experiencia de la guerra y los conflictos nacionalistas están presentes en la mayor parte de esta producción literaria, también lo es que en muchos casos se narran intercalando hechos reales y ficción o haciendo confluir en los personajes ficticios de las obras diferentes experiencias propias con otras imaginadas o ajenas a sus vivencias. En cualquier caso, predomina el narrador homodiegético que en general adopta el papel del protagonista, los hechos narrados pueden haber sucedido al auto o no pero en todos late un fondo de realidad basada en la propia experiencia de este. Como afirma Elvira Mujčić en varias entrevistas publicadas en diferentes medios de comunicación: "nei miei libri non c'è nulla di non autobiográfico".

\section{Elvira Mujčić: Bosnia de NACIMIENTo, ITAliana de AdOpCión}

Elvira Mujčić es una escritora de origen bosníaco³, nació en 1980 en una pequeña ciudad de Serbia, Loznica. Poco después de su nacimiento, su familia decidió trasladarse a Srebrenica, ciudad en la que vivió hasta el 16 de abril de 1992. Referimos la fecha concreta visto que es importante teniendo en cuenta cómo se desarrollarían los acontecimientos posteriormente en el país. Este fue uno de los últimos días en los que se pudo salir de la ciudad, su familia decide entonces abandonar por un tiempo su lugar de residencia esperando que los conflictos que empezaban en aquel momento se calmaran y la escritora, en aquel momento apenas una adolescente, se aloja junto a su madre y sus dos hermanos en casa de algunos parientes en Bosnia central, su plan inicial era permanecer allí durante dos semanas hasta que el clima de tensión que se vivía en el país se relajara.

Su padre, considerando la decisión algo provisional, decidió quedarse en Srebrenica junto con el resto de varones adultos de la familia. Esa sería la última vez que Elvira viera a su padre, el conflicto se alargó en el tiempo y la ciudad de Srebrenica fue una de las más masacradas durante las operaciones de exterminio del ejército serbobosnio. La gran mayoría de los familiares de Mujčić que se quedaron en la ciudad desaparecieron durante la masacre, incluido su padre, cuyo cuerpo no ha sido aún encontrado.

En la primera de sus novelas, completamente autobiográfica como ya hemos explicado, narra el momento en el que desaparecen tanto su tío como su padre. Ante la inminente entrada del ejército serbio en la ciudad cada uno toma una decisión, el tío decide confiar en sus propias fuerzas, el padre en los cascos azules: el trágico final de ambos desvela que no había escapatoria posible.

Mio zio si fidò solo delle sue forze e decise di andare per il bosco [...] un mese dopo la caduta di Srebrenica un signore ci raccontò di aver(lo) visto tra migliaia di cadaveri [...]. Non ci abbiamo creduto mai. Abbiamo continuato per anni ad aspettare che tornasse. Mia nonna, credo, aspetti ancora.

Mio padre ha preso un'altra decisione. Lui si è fidato dell'Onu [...] si è incamminato verso la loro base [...] pare fosse fiducioso fino alla fine [...] lo caricano su un camion e lui, timidamente, alza la mano in segno di saluto. Assicura che ha sorriso. Dev'essere uno di quei sorrisi tristi, quell'allargare le labra per dare forza a chi lo guardava.

Noi eravamo già in Italia; guardavamo quella morte in diretta, tra disperazione, lacrime e svenimenti (Mujčić, 2007: 26).

3 El término bosníaco se utiliza para designar a los bosnios de confesión religiosa islámica, mientras que bosnio se refiere sólo a la nacionalidad.

Revista Internacional de Culturas y Literaturas, abril 2017 
Y en efecto, la escritora, adolescente en aquella época, había conseguido llegar al país transalpino. Después de salir de su ciudad y tras una breve estancia en casa de familiares, consigue llegar con su madre y sus hermanos a un campo de refugiados en Croacia; allí pasarán varios meses antes de trasladarse definitivamente a Italia, país en el que se establecerán definitivamente y donde aún hoy desarrolla su carrera profesional como escritora y traductora en Roma.

\section{La obra de Elvira MujČić}

La autora ha publicado hasta el momento cinco novelas contadas en clave autobiográfica, no tanto - y no siempre - por los hechos que narra como por la temática que trata en todas ellas: la guerra de Bosnia, sus consecuencias y el tema de la inmigración. Queda patente que estas novelas se basan en su propia historia vital y entronca con la de otros individuos anónimos que, al igual que ella, vivieron el drama bélico y siguen conviviendo con sus consecuencias en la actualidad.

\section{Al di là del caos. Cosa Rimane dopo SRebrenica}

Su primera obra, Al di là del caos. Cosa rimane dopo Srebrenica, publicada en 2007, es una novela esencialmente autobiográfica en la que la autora ha querido dar a conocer la masacre que se vivió en esta ciudad a través de sus propias vivencias, las experiencias que vivió en aquel momento y las que vinieron a la postre a consecuencia de las primeras. La novela es una suerte de denuncia abierta a quienes son responsables de una masacre y salen impunes. Es a la vez un viaje físico y un viaje psicológico que la ha llevado a recorrer la misma senda que un día la trajo a Italia, pero en sentido contrario hacia Srebrenica. Es una novela escrita con el ánimo de aliviar el peso que suponía para ella la tragedia de su país, la experiencia de la guerra y de la migración. Había comenzado a leer ávidamente ya desde que era muy pequeña y durante su estancia en el campo de refugiados en Croacia la lectura la había ayudado a soportar el momento, por eso decidió escribir "nella speranza che la scrittura, le storie mi salvassero un po' dalla vita e mi aiutassero a dare un senso alla realtà" ${ }^{4}$.

Al di là del caos es un libro sobre la guerra y el proceso de crecimiento de una joven durante esos días. La autora nos cuenta su historia y la de su país a través de episodios significativos de su vida: el duro trance de tener que enfrentarse a una guerra, la experiencia vivida en el campo de refugiados o el hecho de sentirse extraña en Italia, entre otras emociones. El relato salta de un momento a otro sin orden cronológico en una línea temporal por la que se desplaza aleatoriamente trasladando al lector de Bosnia a Italia de modo intencionado con el único fin de que este entienda cómo se

4 Declaraciones directas realizadas por la propia autora en el transcurso de varias entrevistas personale mantenidas con ella. siente ella misma, porque así siente su propia identidad, continuamente a caballo entre su pasado y su nueva vida en Roma.

\section{E SE FuAD AVESSE AVUTO LA DINAMITE}

El resto de sus novelas, como decíamos, no son puramente autobiográficas en cuanto a los hechos narrados, pero sí en cuanto a los temas y los caracteres de los personajes a los que otorga rasgos propios de ella misma y de su forma de pensar. Ejemplo de ello es su segundo libro, E se Fuad avesse avuto la dinamite?, en el que la autora divide su personalidad y su perspectiva por lo que respecta a la guerra entre dos personajes diferentes: el personaje principal, Zlatan, y el tío de este.

Zlatan encarna el personaje de un joven emigrado a Italia que rechaza todo tipo de odio y venganza y a quien la experiencia migratoria le ha ayudado a tener una visión más abierta del mundo, pero para quien es aún complicado aceptar que el país que él conoció y vivió ya no existe tal y como pervive en sus recuerdos. Por otra parte, encontramos a su tío, un excombatiente y residente en Visegrad, otro de los escenarios de la tragedia bosnia, que cuando se siente atacado por su sobrino que lo califica de nacionalista responde así:

Sveglia! Per tuo padre è nazionalismo tutto ciò che cerca di far sentire la propria voce contro l'ingiustizia. Ragiona come gli europei e gli americani, che pensano che con il trattato di Dayton si sia risolto tutto e che bisogna smettere di ricordare, di cercare giustizia e che il miglior modo per vivere è fare i cosmopliti di cosmopoliti e tolleranti. Ma non funziona cosi! Io non ho mai votato per un partito nazionalista, non mi sono messo a studiare lislam e non sono diventato un fervente credente Semplicemente, non sto zitto, non abbasso la testa, non fingo multiculturalismo perché prima voglio giustizia. (Mujčić, 2009:89)

Encontramos, por lo tanto, esa doble vertiente personalística de la autora. Por un lado, la visión de Zlatan que quiere respuestas pero no quiere aferrarse al dolor ni al odio y, por otro, la del tío Nazid, que se enfrenta a su propia rabia al ver cómo el seguir hacia delante implica que se le niegue el dolor natural e inevitable ante la tragedia.

El argumento se centra además en el debate sobre la necesidad de tener memoria histórica y la obligación de seguir adelante superando el pasado. Zlatan reflexiona así:

Volevo mantenere i miei ideali, senza i quali non avrei potuto vivere. In questo ero come mio padre. E non sapevo se il mio modo di fare fosse giusto o se invece avesse ragione mio zio. Che continuava a vivere dentro l'inclubo. Tutti in questo paesino ci vivevano dentro. Eppure erano passati quasi 15 anni dalla fine della guerra ma per la gente pare quasi si tratti di due mesi fa! Forse bisogna fare cosi puer per conservare la memoria. Ma a che prezzo. Tutta una vita spesa a conservare la memoria, rivive un altro che non richieda di morire ad ogni passo? (Mujčić, 2009: 96) 
Cualquiera de los temas presentes en la novela son temas tocantes para la autora y que conciernen a su propia vida: la compleja relación entre los bosnios que viven en el extranjero y aquellos que han permanecido en el país, el vínculo entre padres e hijos una vez pasada la guerra, la extraña sensación de llegar a sentirse en algunas ocasiones extracomunitario en el país que los ha acogido y los ha visto crecer durante años, la percepción de encontrarse siempre entre dos lenguas, entre dos tierras, entre dos culturas.

\section{DIECI PRUGNE AI FASCISTI}

Otro de sus libros en el que, contando una historia completamente diferente, toca los mismos temas es precisamente su última novela, Dieci prugne ai fascisti. De nuevo un viaje es el protagonista de la novela. Los protagonistas son los integrantes de una familia bosnia con muchos puntos en común con la propia familia de la autora, similitudes que obviamente no son elegidas por casualidad ni caprichosamente. Estos personajes, afincados en Italia desde la década de los noventa pero profundamente ligados a las tradiciones de la propia tierra, deben volver a Bosnia para enterrar a la abuela, principal soporte de la memoria y del pasado común, y que dejó todo dispuesto antes de su repentina muerte para recibir las exequias en su país natal.

La narradora será en este caso una de las nietas en la que Mujčić ha querido plasmar su reflejo y a través de cuya voz, con mucha dosis de ironía, delineará los sentimientos de un pueblo y de su familia. Despedirse de su abuela supondrá para la protagonistanarradora un viaje por los recuerdos y un intento de reconciliarse consigo misma.

El viaje físico que realiza la protagonista hacia Bosnia junto a sus dos hermanos es una suerte de migración inversa, es un volver hacia atrás para encontrarse con un pasado al que la guerra dejó sin futuro, es un modo de intentar cerrar el ciclo y comprenderse a sí mismos.

Il pullman correva, cumuli di nuvole ci venivano incontro come se dovessero scagliarsi sul parabrezza. Volavamo sulla strada, mentre quel gruppo di nostalgici comunisti bosniaci stanchi e con le braccia indolenzite cantava canzoni di altri tempi e soprattutto di altri mondi.

Per la prima volta, dopo molti mesi, mi sembrava di andare da qualche parte e pure nella direzione giusta.

Dopo una mezz'oretta di viaggio, il fervore dei canti prese a indebolirsi, fino a spegnersi e lasciarci in un silenzio strano, sconsolato e malinconico, pieno di a spegnersi e lasciarci in un silenzio strano, sconsolato e malinconico, pieno di
discorsi incompiuti il cui tempo è passato. Come quando ti imbatti in una vecchia conoscenza e rimani a bocca aperta, imbarazzato, cercando qualcosa da dire, una maniera per riallacciare i fili di un'empatia ormai anacronistica.

Due ore e mezza di braccio fuori dal finestrino, ecco il mio ultimo (e unico) sacrificio per un paese che non c'è (Mujčić, 2016: 113 - 114).
Elvira Mujčić introduce a menudo la imagen del viaje en sus obras como una especie de reconciliación consigo misma y con sus raíces. Unas raíces de las que llegó a renegar en el momento en que empezó a amar Italia: odiaba Bosnia porque se sentía expulsada de sus entrañas, amar Italia le parecía una venganza merecida. Sin embargo, volver a su país natal le hace redescubrir el amor por este y la rabia y la melancolía lacerante que la hacen sentirse unida irremediablemente a esta tierra, como si una parte de ella nunca hubiera salido de allí.

Si bien es cierto que la autora manifiesta abiertamente la incertidumbre que ha sentido siempre al no sentir que perteneciera a un lugar ni a otro, como ella misma declara el hecho de emigrar de alguna manera te rompe, se produce una fractura entre lo que eras y en lo que te conviertes, Elvira Mujčić lo describe como una especie de "assenza duplice" ante el sentimiento de no pertenecer, en su caso, ni a Italia ni a Bosnia-Herzegovina. En este sentido relataba un recuerdo en una entrevista ${ }^{5}$ publicada a raíz de la publicación de su última novela:

Mi ricordo, in questo senso, una delle prime volte che siamo tornati in Bosnia Erzegovina. Era il 1997 e avevamo lasciato il nostro Paese già da tre anni. In Italia Erzegovina Era il 1997 e avevalo mi lamentavo Erzegovina, hocominciato a dire a mia manma che volevo andarmene, perchen era affatto il Paese che ricordavo. Sul traghetto del ritorno, da Spalato ad Ancona, io me ne stavo zitta, non parlavo, al che mia mamma mi ha detto: finalmente un posto in cui non ti lamenti... in effetti, stavo bene solo sul traghetto.

La trama que la autora desarrolla en su última novela no es una historia real aún cuenta con la presencia de su abuela en su vida - pero es absolutamente real el sufrimiento descrito en la novela, la desolación y el desconsuelo de quien ha perdido a familiares o seres queridos durante la guerra y cuyos cuerpos no han sido nunca encontrados para poder ser enterrados, la propia autora nos lo contaba así en una conversación mantenida con ella:

Mi sono chiesta come si può, se si può, elaborare a livello famigliare un peso del genere. Ho guardato la mia vita, quella dei miei fratelli e di mia madre e vi ho trovato tracce

emotivamente, ma l'ho inserito in una storia che non è esattamente accaduta.

Justifica de este modo la necesidad de narrar un entierro lleno de vicisitudes, quiere dejar constancia de ello como un símbolo de lo que le gustaría poder hacer algún día con sus seres queridos desaparecidos.

\section{Conclusiones}

5 La entrevista completa puede consultarse en https://www.balcanicaucaso.org/aree/Bosnia-Erzegovina/ Dieci-prugne-ai-Fascisti-intervista-a-Elvira-Mujcic-172039 [Fecha de consulta: 15/04/2017] 
En definitiva, en todos los libros escritos por Elvira Mujčić podemos encontrar rastros testimoniales, incluyendo su primera novela que es un testimonio en todo su conjunto. Dichos indicios los podemos analizar en diferentes elementos de sus obras; bien en el carácter de los propios personajes, bien en los escenarios en los que se mueven, pero sobre todo en las experiencias y en los sentimientos relatados en cada viaje que Mujčić nos invita a hacer con ella. Viajes que, como ya hemos apuntado, no son exclusivamente físicos, travesías también psicológicas y emocionales en las que la autora, con una gran capacidad narrativa, entrelaza hechos externos y aspectos de introspección personal.

En cada una de sus obras descubrimos una identidad fragmentada, pero igualmente una identidad formada a partir de su condición de yugoslava, de bosnia y de italiana: "La nostra identità si è allargata ancora e mescolata, interrompendo il nostro processo di balcanizzazione" (Mujčić, 2016: 104).

\section{REFERENCIAS Y BIBLIOGRAFía}

Bukvić, E., Il nostro viaggio. Identità multiculturale in Bosnia Erzegovina, Roma, Infinito Edizioni, 2008.

Fracassa, U., "Strategie di affrancamento: scrivere oltre la migrazione", Certi confini. Sulla letteratura italiana dell'immigrazione, Vignate, Morellini Editore, 2010, pp. 179 $-199$.

Matvejević, P., Mondo "ex": Confessioni, Identità, ideologie, nazioni dell'una e dell'altra Europa, Milán, Garzanti, 1996.

Mengozzi, C., Narrazioni contese. Vent'anni di scritture italiane della migrazione, Roma, Carocci Editore, 2013.

Mujčić, E., Al di là del caos. Cosa rimane dopo Srebrenica, Segrate, Infinito Edizioni, 2007.

Mujčić, E., E se Fuad avesse avuto la dinamite?, Segrate, Infinito Edizioni, 2009.

Mujčić, E., Dieci prugne ai fascisti, Roma, Elliot Edizioni, 2016.

Quaquarelli, L., Certiconfini. Sulla letteratura italiana dell'immigrazione, Vignate, Morellini Editore, 2010. 